\title{
Thomasian Surgeons Celebrate Milestones Amidst Pandemic
}

\author{
May 18, 2020
}

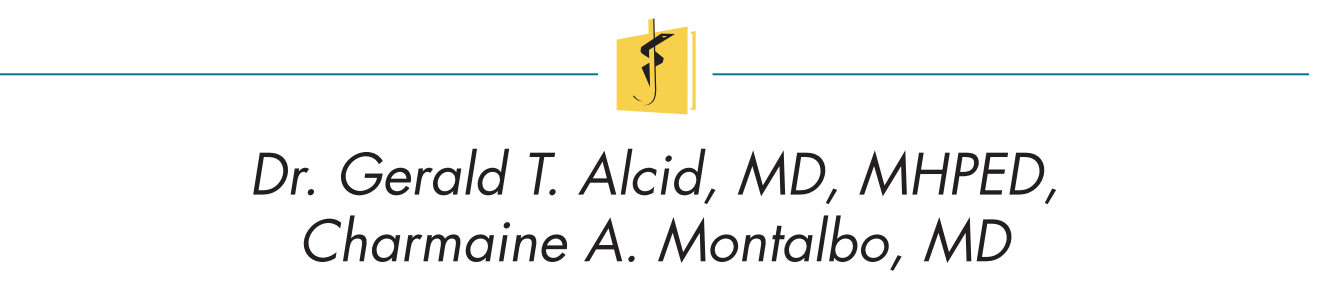

"We take Pride in winning this Award on behalf of the Department of Surgery with our rich tradition of competent, compassionate Thomasian Surgeons" - Dr. Gerald T. Alcid, MD, MHPED, Chair, USTH Department of Surgery

The University of Santo Tomas Hospital, Department of

\section{HEALTHCAREASIA} AW RDS 2020

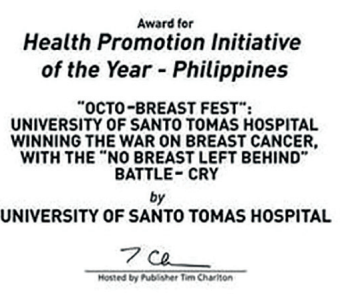

HEALTHCAREASIA
Surgery was lauded for their health care delivery, indigency program and promotion of Breast Cancer Awareness. The Health Care Asia Awards 2020 held virtually last May 14, 2020 recognized the Department of Surgery as the recipient of the HealthCare Promotion Initiative of the Year Award for the OctoBreast Fest Project held last October 2019 in cooperation with the UST Hospital Outreach and Indigency Program.

Breast Cancer Awareness Month is a worldwide annual campaign taking place in the month of October, involving thousands of organizations to highlight the importance of breast awareness, education and research. Last October 2019, The UST Hospital Department of Surgery in cooperation with the UST Hospital Indigency Program, organized "Oc-

Charmaine Montalbo

chamontalbo@gmail.com

Surgery Resident, Department of Surgery, University of Santo Tomas Hospital tobreast Fest" a month-long celebration of breast cancer awareness and women empowerment. The campaign was focused on four key areas and celebrated four festivities: risk and prevention of the disease, early detection, diagnosis and treatment.

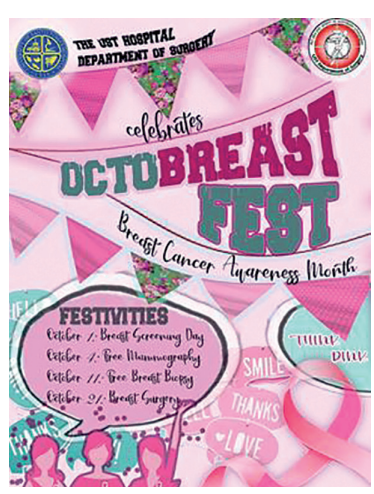

Approximately 1 in 13 Filipino women will develop invasive breast cancer during their lifetime, according to the Philippine Council for Health Research and Development. A free breast cancer screening and lay forum happened last October 1, 2019 at the St. John Macias Division, Gazebo Garden.

About 69 women, 18 years old and above, participated and learned the nature of breast cancer, misconceptions of the disease and how to perform self-breast examination. "There can be life after breast cancer, the pre-requisite is early detection". This was strengthened during the lay forum when a 63-year-old stage II breast cancer survivor "Nanay Virginia" stood and spoke up her journey on how she fought her battle with breast cancer. In spite of it all, she shared her story with humor and grace.

As early as age 40, every woman should receive a yearly screening mammogram. Fifteen out of 69 Octobreast screening day participants who had positive breast examinations and eligible for recommended annual screening underwent a free 


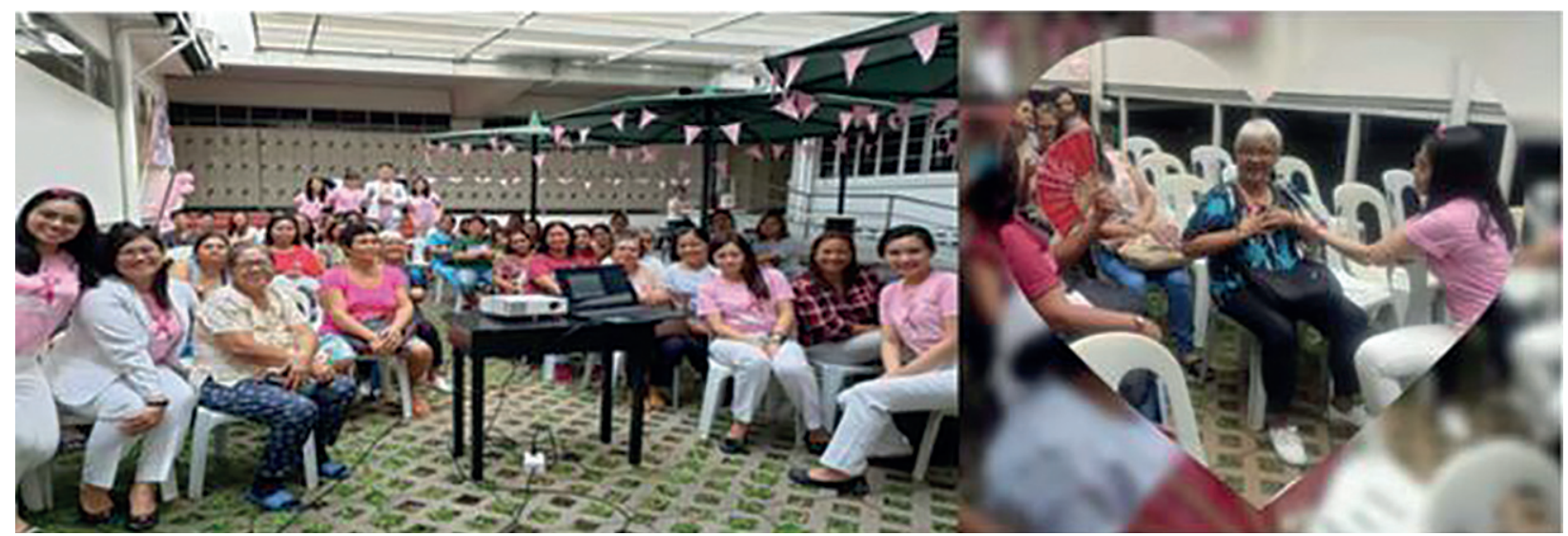

mammography in collaboration with the Department of Radiology-Breast Unit at the Benavides Cancer Institute. They were scheduled for the procedure from

\section{October 3-8, 2019.}

If a woman had a breast lump or an abnormal mammogram, she needed a breast biopsy to rule out cancer. With the help of Ambulatory Care Services-Department of Surgery, "3 out of 69" Octobreast participants had a free core-needle biopsy last October 11, 2019.

The department's campaign is to stop women dying from breast cancer and making sure that everyone affected by breast cancer receives the best possible treatment and service.

October 21, 2019 - the fourth part of the Octobreast festivities "Free Breast Surgery". In collaboration with the Department of Anesthesia and St. John Macias operating room staff, "3 out of 64 women" confirmed positive for breast carcinoma and one patient diagnosed at the Ambulatory Care services was successfully operated on. Most postoperative cancer patients feel powerless and depressed. But the entire team, the department, consultants, residents and clinical clerks gave their best effort and emotional support for these patients because a strong support system is still the best weapon against cancer.

Four key areas and goals achieved - risk and prevention of the disease, early detection, diagnosis and treatment. The Department of Surgery was able to reach out not only patients who participated in their month-long festivities but also through the use of social media as a platform, was able to educate thousands of women and families that October is Breast Cancer Awareness month. By simply posting and sharing in social media is life changing and life saving.

"No Breast Left Behind", with increased awareness of breast cancer, prompts early detection and diagnosis leading to timely and effective treatment. The UST Hospital Department of Surgery would like to thank the following departments for this event which would not be possible without their cooperation, UST Hospital Administration and Indigency program, The Department of Radiology-Breast Unit, The Department of Anesthesia, Ambulatory Care Services and the Operating Room Staff-St. John Macias.

Amidst the corona virus pandemic, the Department of Surgery headed by Dr. Gerald T. Alcid celebrates this milestone and shares this first international award of the department to all the staff and their beloved institution, University of Santo Tomas Hospital. Dr. Alcid, as a cancer surgeon, considered this

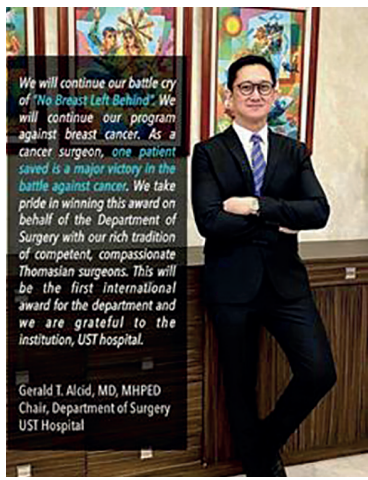
as a major victory in the battle against breast cancer. He said "We take Pride in winning this Award on behalf of the Department of Surgery with our rich tradition of competent, compassionate Thomasian Surgeons." The department will continue its battle cry of "No Breast Left Behind" and will create innovative ways to address and cater to the needs of their cancer patients despite the challenges brought about by this COVID19 to the healthcare system. 
